\title{
NATURE-STUDY AND AGRICULTURE IN RELATION TO EDUCATIONAL MOTIVES AND PURPOSES.
}

By H. N. Goddard,

State High School Inspector of Agriculture, Madison, Wis.

We are told that on the occasion of the visit of a great preacher to Athens, he found the "Athenians spending their time in nothing else, but either to tell or to hear some new thing." In education we have had much of this search for new things. The search has led to much foolish waste of educational energy, to many silly fads and to much educational exploitation of children. At the same time it has led to progress. What we need most now and what we have always needed in education in order that real progress may be rapid and sure is educational balance-the ability to sift out and retain what is tried and best in the old and unite with it what is sane and reasonable in the new. Changing social, economic and political conditions are bound to call for revised methods and the use of new materials. At the same time, it is necessary to divest ourselves of useless traditions. Our educational system has received and assimilated, with more or less success, many of these new things. Whatever indigestion or educational dyspepsia may have resulted, we have, nevertheless, made rapid growth and, today, America may honestly boast of one of the best educational systems in the world, although we may yet have many things to learn from other countries. A long list of hobbies has successively occupied the educational stage. The kindergarten, object teaching, correlation, child study, Herbartianism, recapitulation, industrial arts, Naturestudy, plays and games, the Montessori method, vocational education and many more have appeared one after another. We have attempted to apply the psychology of interest and attention, of habit, of sense training and apperception, of adolescence and of the biogenetic conception. We have striven to make education practical. In these days we are socializing school subjects, motivating our teaching and vitalizing the school. Good has no doubt come from all of these but the astonishing thing about it all is that the children on whom all of these have been tried, though possibly slightly distorted or intellectually stunted at times, have usually come through in a pretty good state of intellectual preservation. At the same time they have grown up and have been able to meet the duties of life with a greater or less degree of success. All this is perhaps a great tribute to the powers of growth and development in the average child. 
Whatever good may have been gained from each of these notions, it is nevertheless true that many leading educators are yet saying that much of our present education is formal, isolated from real life problems and comparativelý ineffective. While I do not wish to assume the part of the critic, yet I think we must confess that there is at least room for further improvement. One of the greatest dangers in all new educational ideas is the tendency to systematize each according to the notion of the adult mind, until most of the life and value have been squeezed out of it for the child. Prof. Charters of Missouri University says in a recent book that every subject when first introduced into the curriculum had a vital value, but that so far, not one has had much life left after submitting to the systematizing process. Nature-study came in response to a keen demand of child-life and child-development, but it immediately fell a prey to the scientists, the "integument men," the anthropologists, the course of study-makers, until its very life was gravely threatened. Fortunately, it has refused to be stereotyped, but as a result, it occupies a comparatively small place in most schools. It has been left for the boy scout movement to really adapt it to the nature of a boy. The fixed program and the formal class exercise made it impossible for the school to do this.

More recently agriculture has demanded attention and there is much encouragement that this will not only realize its own vital value, but that it may do much in vitalizing all the other school work. There is some prospect that school work in this subject may actually be able to function in the practical life of the community. Nevertheless, there is grave danger that it, too, may be a victim of the standardizing habit and as a result may lose a large part of its vital value. In order that it may not, it is necessary that we should develop a clear understanding of its values and of the methods and motives which must be depended upon to arouse interest, secure effort and give the work life value. My task is to point out some of these values and motives and show how they become modified as we pass from the Nature-study to the agriculture viewpoint:

Before attempting to do this, let us look for a moment at the present educational situation. We are trying, in these days, to adjust ourselves to the idea of education in a democracy. This means universal education. As faith in this idea has become deeply fixed, we have been breaking away more and more from old traditions. At the present time, we are asking in educational 
circles as never before, how can we make education really efficient in meeting the problems of democracy? We no longer look upon the school as an institution for a selected few. The function of the school is, therefore, no longer to train a few people for socalled learned professions, or fit a small number for higher institutions, but it is to provide a training which will best lead every boy and girl into intelligent, useful and successful living. We have come to recognize that our present educational system has tended to train pupils away from the life they are living, rather than to fit them for it. As a result, country boys and girls have too often been anxious to get away from the farm, while young people generally have built up an ambition to find some life easier than their parents have had. A false line of separation has grown up between the work necessary for a livelihood and those activities which contribute to enjoyment. The present viewpoint of education is away from these notions. According to this new viewpoint, the highest product of the schools is not the one who knows the most or who has the greatest mastery of certain subjects. It is rather the person who is most able to meet the duties of life efficiently, and at the same time appreciatively. This means making a living, but it means also the discharging of the duties of citizenship and the capacity for wholesome use of the leisure of life. This viewpoint is well expressed in the ideal of the Danish high schools in the following: "It is not the business of the high schools to give a few facts of this subject or a few facts of that, so much as to awaken the minds of its pupils, to arouse in them a feeling of brotherhood, to give them a knowledge of themselves and of life. We want our pupils to say when they leave: 'Now will I go back to my work more fully realizing the meaning of it and more deeply feeling the dignity of it." " Such a view seems to demand first of all a general education. This should give command of the tools of knowledge. It should develop right habits and appreciations and put meaning and intelligence into life. It should further prepare for the best citizenship and the highest social service.

In addition to this general education, the school should also provide some training to help every person to be able to gain a competent livelihood in some line, which will not only furnish proper financial support, but which will also be suited to the tastes and talents of the individual. For this purpose the school should help the pupil to find himself with reference to some vocation-that is. he should discover what life activities make 
the strongest appeal to his tastes and talents. When this is done the school should further provide opportunity for him to develop some skill in the work of this field. This should not be merely mechanical skill, but it should include an intelligent and appreciative understanding of the work. It has come to be the firm conviction of many educators that these two phases of education should not be carried on apart from each other, but they should be so blended that the general education shall furnish a large knowledge and a wide perspective, for an understanding and appreciation of the vocation, while the vocational work helps to vitalize and motivate the general work. These two should not only be closely blended at any particular time or period, but the one should lead gradually into the other as the school course progresses. In the early grades the vocational makes, of course, a minor, and perhaps hardly perceptible, appeal. However, it finds a sudden and rapid awakening in the upper grades and finally becomes strong and even predominant in the upper years of the high school.

With these views of education before us, I am now ready to consider the main point of my topic. The Nature-study fits, of course, most completely into the early part of the scheme. Its appeal to the child is strong because of its wide freedom and because of its pleasing relations with his own pleasurable activities. The child at this stage is stimulated most strongly through his senses and Nature furnishes an inexhaustible array of new and strange materials which please the eye, attract the ear, stimulate the imagination. Again, all his racial tendencies lead him to love the fields, the woods, the streams and the out-of-doors. Furthermore, since his own organism finds most natural and most pleasing expression through activity, he finds his most ardent interest in activity in the world about him. Nature, and especially living Nature, furnishes this activity in never-ceasing cycles. This appeal is especially strong because of the constantly changing scenes and situations which Nature affords. A large part of every child's education consists in making conquest of this strange and ever-changing world. The schools have shown far too little recognition of this fact. This interest in activity soon develops an ardent desire to discover what things in Nature can do, and then the child wants to know how they do it. It should be noted that living, changing Nature and the spacious out-of-doors make the strong appeal. The school has been exceedingly slow in adapting its stereotyped classroom 
methods to these well-known child interests. Indeed, much high school botany and perhaps other science, which might have made a strong appeal to interest and effort, has been dead and fruitless because of failure to present this side. It is not information about Nature or even stories of Nature that appeal most strongly to the child. What he wants is sympathetic acquaintance with Nature and an understanding of her ways. This should lead to a right attitude which is more moral than intellectual, and which should finally develop both a knowledge and a spirit leading to the preservation of useful things and control of those which are harmful. Educationally this study not only develops sympathetic knowledge, but provides also a most vital intellectual training, and a concrete experience which is able to vitalize much of the more formal work of the school.

As pupils advance toward higher grades, new interests become dominant and should lead to a modification of the work. These new interests take the form of an eager desire to appropriate Nature's resources and to be able to manage and control her forces. 'Likewise the study of wild animals makes a strong appeal to love of adventure and thrilling experience. Woodcraft finds a ready response. At the same time, the desire for ownership or possession and for the profits of productive enterprise begins to appear and grows stronger as the upper grades are reached. The boy comes to want to be a man and wishes to imitate man's achievements. As this interest becomes predominant, it gives a motive which should gradually modify the work. Gardening work and the raising of plants may well have formed a part of the Nature work considerably before the seventh and eighth grades. Such work as a part of the Naturestudy should be given larger attention as the grades advance and should gradually be merged into what may be really called agriculture in the seventh and eighth grades. Formal agriculture should not be started before the beginning of the seventh grade. The work before this time should be generalized with the Nature-study, and not taken up as a distinct subject.

This agriculture of the seventh and eighth grades should not be treated as an informational subject or even as elementary science with simple observation and experiment. There is little motive for such work. It should be treated rather as an industrial art. We hear much about the general culture of a brief informational course in agriculture to help pupils to appreciate farm life and to learn how food products are raised. 
I am extremely skeptical about this idea. Real motive is lacking and such study will almost certainly lead to indifference if not positive dislike. The only way to appreciate the farm and appreciate how food products are raised is to get into the soil and make it give up, to your labors and care, the golden treasures of fruit, of grain or of vegetables. There is already too much appreciation of the farm by those who don't want to live on it but who prefer to wear fine clothes and keep their hands clean in the city. The work should have for its central aim the carrying out of certain surveys and projects relating to farm practice which is adapted to the conditions of the locality. With this practical work, motivated and limited by it, there should be some instruction work. I am not at all certain that any instruction work should be given except as the practical work furnishes the motive and gives the basis for it. Our plan. of a daily recitation period carried over the usual school year is poorly adapted to the needs of this work. We have yet to devise effective methods of doing this work in the upper grades. Unless we can do this, agriculture is likely to fail. As a purely informational subject or even as' a science subject with suitable experimental work, I have little faith in it, either in the upper grades or in the high school. Treated in this way it is likely to be made as dead and as devoid of interest as the specialist's type of physics is to the average high school girl. Elementary science, teated with a fair degree of skill, would be far preferable. Even a poor treatment would be better, since this would not drive young people away from the farm. We have had far too much of this kind of agriculture since it has been introduced into the schools. The only motive on which the work can be based successfully is this desire for ownership and possession, and the interest in utilizing Nature's resources for some worth-while result. A boy likes to do any piece of constructive work which brings to him something worth possessing. The interest is heightened in the case of raising farm or garden products by the growth process, which affords interesting change and development from day to day. Again, an exhibit of products and the final sale of what was produced serves to greatly emphasize the worth-whileness of a project, and this strengthens the motive for effort on the part of the pupil. Rivalry in itself is a powerful motive with us all in any activity we engage in. Besides the boy at this age wants to be a man and therefore to achieve what men are achieving. When he 
can not only raise more corn or potatoes than his schoolmates, but can beat out his father and the neighbors, the motive again is greatly intensified. All these motives are lacking in textbook or laboratory agriculture.

Again, the agriculture work in the upper grades may be looked upon as of a prevocational nature. The pupil is given a chance to find out what practical agriculture is, and to learn what results may be expected from such work. He thus learns whether this is what he likes or can do most successfully. Later, when he enters high school he is ready for this or for some other line of work.

In the high school it is believed the agriculture should become strictly vocational, that is, it should be for the purpose of enabling the pupil to develop a larger intelligence and greater skill in farm practice, with the definite idea of making this a life work. Not that he must here make any such final decision, but that he may be trained at least for this in case he continues to find himself adapted for it. We have now a number of high schools in Wisconsin where such courses are being given and where, as a result of the course, many boys are planning to make farming their work. Here again the central line of work should be the project in which the student actually carries through some piece of farm practice and, as far as possible, secures a profitable result. Here in the high school, however, the course may be much strengthened and the understanding of problems may be greatly widened by the application of the knowledge of the sciences, of economics and other high school branches. The chief motive, however, will be still much the same, viz: the carrying out of productive work for the securing of a worthwhile result. The larger knowledge and better understanding of problems may make some appeal, but this will be secondary. Again, simply studying about agriculture and performing laboratory experiments will fail to make any adequate appeal to the high school pupils.

The laboratory for agriculture should be mainly the soil and the real farm products. Certain laboratory experiments are, indeed, desirable when properly related to actual experience, but agriculture of purely informational and laboratory character has, $I$ believe, no more value and can arouse no greater motive in the high school than an informational course in manual training or domestic science or typewriting. "The true place of agriculture, as of these other subjects, is that of an industrial art. 
Such treatment will not only interest the pupil but it will have high educational as well as vocational value.

We have tried to show the place of the Nature-study and of the agriculture in the curriculum and have tried also to show how the one merges gradually inta the other. We have further tried to show how the Nature-study motive changes, not suddenly, but gradually, until a distinct motive provides the true basis of the agriculture. Nature-study has its large place in the earlier grades, where it should be a generalized study of the child's natural surroundings. The desire to do something for a practical result grows rapidly and leads the pupils to give an eager response to the industrial arts. At the beginning of the seventh grade, the agriculture makes a most valuable subject for such treatment. The work has a prevocational value in the upper grades, and this gradually changes into a more strictly vocational value in the later years of the high school, where the work should still be treated as an industrial art or vocational subject linked up with and strengthened by the general studies of the high school, especially the sciences. There should be definite instruction work, but this should be linked up with and motivated by the practical doing of suitable projects related to the farm. Some of these projects may be school projects but there should also be home projects, which actually carry the school work over, so that it functions in the home. It is the business of those charged with agricultural work to devise effective methods of accomplishing these results. The fixed methods of the schools as they are today are the least adapted to this work of any of the industrial subjects. At the same time the right kind of agricultural work is a most fundamental need. A purely informational course or a course treated purely as a science is in my judgment of very doubtful value, since it lacks motive. Such cultural value (whatever people may mean by that term) can be obtained far more effectively by the right kind of science work. Agriculture is an industrial art, and treated as such has high educational value, if indeed, it is not itself also in the truest sense highly cultural. 